\title{
Atomoxetine Hydrochloride
}

National Cancer Institute

\section{Source}

National Cancer Institute. Atomoxetine Hydrochloride. NCI Thesaurus. Code C47405.

The hydrochloride salt of atomoxetine, a phenoxy-3-propylamine derivative and selective non-stimulant, norepinephrine reuptake inhibitor with cognitive-enhancing activity.

Although its precise mechanism of action is unknown, atomoxetine appears to selectively inhibit the pre-synaptic norepinephrine transporter, resulting in inhibition of the presynaptic reabsorption of norepinephrine and prolong ation of norepinephrine activity in the synaptic cleft. The effect on cognitive brain function may result in improved attention and decreased impulsivity and activity levels. 